\title{
Effectiveness of MTA pulpotomy in primary molars: A critical assessment of relevant studies
}

\section{Abstracted from}

\section{Anthonappa RP, King NM, Martens LC.}

Is there sufficient evidence to support the long-term efficacy of mineral trioxide aggregate (MTA) for endodontic therapy in primary teeth? Int Endod J 2013; 46: 198-204.

Address for correspondence: Robert P. Anthonappa, 17 Monash Avenue,

Nedlands, Perth, WA 6009, Australia. E-mail: robert.anthonappa@uwa.edu.au

\section{Question: Is mineral trioxide aggregate (MTA) effective for long-term endodontic therapy in primary teeth?}

Data sources Medline.

Study selection Studies that evaluated the efficacy of MTA as a pulpotomy medicament in primary teeth were included, abstracts, observational studies and case reports were excluded. Only English language studies were considered.

Data extraction and synthesis Studies were assessed and graded by two reviewers using a weighted criteria based system and a qualitative summary of the evidence provided.

Results Twenty-two studies were included, 17 studies compared MTA with formocresol, four studies compared MTA with calcium hydroxide, ferric sulphate, Portland cement, calcium-enriched mixture cement (CEM) and one study compared white MTA with grey MTA.

Conclusions Based on the assessment criteria employed, there was no evidence that MTA was better than present materials and techniques as a pulpotomy medicament.

\section{Commentary}

The goal of this article is to critically assess data quality from previously published studies that discuss longterm effectiveness of MTA as a pulpotomy medicament in primary molars. The authors searched Medline through May 2012 for human clinical outcome studies. Grey literature was not searched which led to missing a relevant study by Neamatollahi and Tajik ${ }^{1}$ Non-English language studies were excluded with subsequent risk of language bias.

Twenty-two studies published from 2004 to 2011 were included. These studies compared 683 MTA treated teeth with other pulpotomy medicaments; 533 formocresol, 12 Portland cement, 46 ferric sulphate, 45 calcium hydroxide and 35 calcium-enriched mixture cement treated teeth. In addition, one study compared 136 white MTA with 74 grey MTA treated teeth.

Assessment and grading of included studies were performed by two examiners. The authors utilised the 'modified standard assessment criteria for pulpotomy in primary teeth' for critical assessment of included studies. This assessment tool includes 25 criteria collectively related to: 1) methodological steps; power calculation, randomisation, blinding and whether appropriate statistical tests were used, 2) diagnostic procedures, patient history, tooth selection and fluoride background, 3) outcomes assessment, reporting and follow-up, 4) examiners' train- ing, calibration, reliability and experience, 5) whether published in peer reviewed journal. The assessment tool used a graduated scale with a maximum score of 42 points. Grade A (adequate and fulfil nearly all selection criteria) scores more than 38 points. Grade B1 and B2 (relevant and fulfilling a majority of selection criteria) score from 32 to 37 and from 25 to 31 respectively. Grade C (rejected as they fulfil few of selection criteria) scores 24 points or fewer. ${ }^{2,3}$

The assessment resulted in 13 studies with Grade (C), no Grade (A) studies and nine studies that attained Grade (B). However, the authors concluded that there is no evidence of MTA superiority over other pulp medicaments due to 'low quality of data', thus disregarding the presence of nine (Grade B) studies with relevant quality data. Moreover, quantitative analysis wasn't performed. Thus, the statistical direction of results favouring either MTA or other pulpotomy agent is undefined and a definite conclusion is obscured.

A previously published meta-analysis by Peng et al. ${ }^{4}$ concluded that MTA was statistically superior to formocresol regarding clinical and radiographic success. The authors didn't account for the results of this meta-analysis although quality assessment of included studies was performed using the Jadad scale, which possesses evidence of best validity and reliability amongst 21 quality assessment scales for RCTs ${ }^{5}$.

The 'modified standard assessment criteria' targets many aspects of studies regarding pulpotomy in primary molars. However, this scale didn't follow accepted guidelines during its development nor adequately tested for validity and reliability (internal consistency, face validity, content validity, criterion validity, construct validity and reproducibility). Hence, attained scores or grades may provide false results. ${ }^{5}$ Based on the scale's limitation, readers should interpret information provided in this article with caution.

\section{Ahmed ElKhadem ${ }^{1}$ and Passant Nagi ${ }^{2}$ \\ ${ }^{1}$ Evidence Based Dentistry Centre 2 Paediatric Dentistry Department, Faculty of Oral and Dental Medicine, Cairo University, Egypt.}

1. Neamatollahi $\mathrm{H}$, Tajik A. Comparison of clinical and radiographic success rates of pulpotomy in primary molars using Formocresol, Ferric Sulfate and Mineral Trioxide Aggregate (MTA). J Dent (Tehran) 2006; 3: 6-14.

2. Curzon ME, Toumba KJ. Restoration of primary teeth: clinical criteria for assessment of the literature. Eur Arch Paediatr Dent 2006; 7: 48-52.

3. Fuks $A B$, Papagiannoulis $L$. Pulpotomy in primary teeth: review of the literature according to standardized criteria. Eur Arch Paediatr Dent 2006; 7: 64-71.

4. Peng L, Ye L, Tan H, Zhou X. Evaluation of the formocresol versus mineral trioxide aggregate primary molar pulpotomy: a meta-analysis. Oral Surg Oral Med Oral Pathol Oral Radiol Endod 2006; 102: e40-44.

5. Olivo SA, Macedo LG, Gadotti IC, Fuentes J, Stanton T, Magee DJ. Scales to assess the quality of randomized controlled trials: a systematic review. Phys Ther 2008; 88: 156-175.

Evidence-Based Dentistry (2013) 14, 46. doi:10.1038/sj.ebd.6400931 